\title{
The pharmacokinetics, pharmacodynamics, safety and tolerability of NN2211, a new long-acting GLP-1 derivative, in healthy men
}

\author{
H. Agersø ${ }^{1}$, L. B. Jensen ${ }^{2}$, B. Elbrønd ${ }^{3}$, P. Rolan ${ }^{4}$, M.Zdravkovic ${ }^{3}$ \\ ${ }^{1}$ Novo Nordisk, Department of Pharmacokinetics, Måløv, Denmark \\ ${ }^{2}$ Novo Nordisk, Department of Immunochemistry, Gentofte, Denmark \\ ${ }^{3}$ Novo Nordisk, Department of Clinical Drug Development, Bagsværd, Denmark \\ ${ }^{4}$ Medeval, Manchester Science Park, Manchester, UK
}

\section{Abstract}

Aims/hypothesis. Glucagon-like peptide-1 (GLP-1), a polypeptide hormone secreted by the L-cells in the gastrointestinal tract, has shown promising effects as a new treatment modality for patients with Type II (non-insulin-dependent) diabetes mellitus. However, the pharmacokinetic profile of native GLP-1 with a rapid elimination has limited its therapeutic potential. NN2211 is a fatty acid derivative of GLP-1, which pre-clinically has shown a protracted pharmacokinetic profile, while maintaining its biological activity. This study aimed to investigate the safety, tolerability, pharmacokinetics and pharmacodynamics of NN2211 in healthy male subjects following seven days treatment.

Methods. In a double-blind, randomized, dose escalation, placebo controlled study, healthy male subjects were enrolled at five consecutive dose levels of NN2211 $(1.25,5.0,7.5,10.0,12.5 \mu \mathrm{g} / \mathrm{kg})$. Six subjects were allocated at random at each dose level to active or placebo treatment with a ratio of 2:1. Dosing with NN2211 was performed on day 1, and days 5-11. The 84-h pharmacokinetics and 24-h glucose and insulin profiles were assessed on day 1 and day 11 .

Results. Following s.c. administration the half-life of NN2211 was found to be $12.6 \pm 1.1 \mathrm{~h}$, with a subsequent accumulation index after a daily dose for seven days of 1.4-1.5. There were dose-proportional increases in exposure (AUC and $\mathrm{C}_{\max }$ ) with increasing doses. Overall, there were no statistically significant differences from placebo in the 24-h glucose and insulin profiles. In subjects treated with NN2211 rather than placebo, there was a higher incidence of adverse events, most notably dizziness and adverse events related to the gastrointestinal system. There were no serious adverse events but three subjects were nonetheless withdrawn because of dizziness, fever and nausea. There were no clinically relevant changes in vital signs, ECG parameters, physical examination or safety laboratory parameters. A significantly lower diuresis was observed in the actively treated subjects, without a clinically relevant change in packed cell volume.

Conclusions/interpretation. This study shows NN2211 has a pharmacokinetic profile supporting a daily dose in human beings, but also that subjects treated with NN2211 rather than placebo, had a higher incidence of adverse events, most notably dizziness and adverse events related to the gastrointestinal system. [Diabetologia (2002) 45: 195-202]

Keywords GLP-1, NN2211, Type II diabetes, pharmacokinetics, controlled clinical trial, pharmacokinetics, pharmacodynamics, safety.
Received: 18 June 2001 and in revised form: 9 October 2001

Corresponding author: M. Zdravkovic, Novo Nordisk, Department of Clinical Drug Development, Bagsværd, Denmark, e-mail:mzd@novonordisk.com

Abbreviations: AUC, Area under the curve from time 0 to infinity; $\mathrm{AUC}_{0-24}$, area under the curve from 0 to $24 \mathrm{~h}$; Cmax, maximal plasma concentration; CL/f, oral clearance; DPP-IV, dipeptidyl peptidase IV; GLP-1, glucagon-like peptide-1; LLOQ, lower limit of quantification; $\mathrm{PCV}$, packed cell volume; Rac, accumulation ratio; $\mathrm{t}_{\max }$, time to maximal plasma concentration; $\mathrm{t}^{1} / 2$, halflife; $\mathrm{Vz} / \mathrm{f}$, the oral volume of distribution during the elimination phase 
Glucagon-like peptide 1 (GLP-1) is a polypeptide hormone secreted from the L-cells in the gastrointestinal tract [1]. The antidiabetogenic potential of GLP-1 has been demonstrated in both animal models and in patients with Type II diabetes [2-7]. The effect of GLP-1 in lowering glucose is mediated through a number of mechanisms - notably, a glucose-dependent stimulation of insulin secretion [8], reduction in plasma glucagon concentrations [9], delay in gastric emptying [10], appetite decrease [11, 12], and a direct stimulation of growth and proliferation of the beta cells [13]. The blood glucose lowering effect, as well as the glucose dependency, (i.e., stimulation of insulin secretion only when plasma glucose levels are above normal) of this hormone has made it a promising candidate for the treatment of Type II diabetes[5; $7 ; 14-17]$. In addition, data from patients with Type I (insulin-dependent) diabetes mellitus suggests that GLP-1 could have beneficial effects in this population $[18,19]$.

However, the pharmacokinetic profile of native GLP-1 has severely limited its therapeutic potential as a treatment modality for patients with Type II diabetes. Native GLP-1 is very rapidly degraded by dipeptidyl peptidase IV (DPP-IV) [20], and after s.c. administration the plasma half-life has been assessed to be around $1 \mathrm{~h}$ in pigs and human beings $[2,21]$ and $3 \mathrm{~h}$ in dogs [22]. It has been shown that improved control in Type II diabetes patients with sulphonylurea failure can be obtained by 24-h GLP-1 exposure as compared to $16-\mathrm{h}$, suggesting that a long-acting compound is required to realise full therapeutic potential [23].

To this end it has previously been shown, that fatty acid derivatization provides a protracted action of insulin $[24,25]$, and has also been reported to prolong the half-life of GLP-1 after s.c. administration to dogs [26]. NN2211 is a fatty acid derivative of GLP1 , providing a compound that has shown prolonged pharmacokinetic properties as compared to native GLP-1 in human beings following a single dose [27], while maintaining its biological action both in vitro [21] and in experimental animal models [28-30]. This study was undertaken in order to further investigate the effect of NN2211 in human beings following repeated doses; especially the pharmacokinetic, pharmacodynamic and safety profile after seven days with a daily dose administrated.

\section{Subjects and methods}

Study overview. The protocol was approved by the Independent Ethics Committee in Manchester, UK, and conducted in accordance with the Helsinki Declaration and Good Clinical Practice. Subjects consented to participate in the study in writing after a full explanation of the study had been given. The study was designed as a single-centre, randomised, doubleblind, placebo-controlled, parallel-group dose-escalation trial, with initial single, and subsequent multiple s.c. doses of NN2211 to healthy men. A parenteral formulation of NN2211 and matching placebo was used. Sterility and endotoxin concentrations complied with the European Pharmacopoiea. Five dose levels were studied, $(1.25,5.0,7.5,10$ and $12.5 \mu \mathrm{g} / \mathrm{kg})$ and six subjects were allocated at random at each dose level to active or placebo treatment with a ratio of $2: 1$. Each subject was allocated to one dose level only. Subcutaneous doses were administered as a single dose on day 1 , and followed by once-daily multiple dosing on days 5-11 in the morning between 8:00h-10:00 h. All meals served were standardised, breakfast, lunch and dinner were served 1,4 , and $11 \mathrm{~h}$ after the dose was administered, respectively.

Subjects. Altogether 30 healthy men (age $18-45$ years; BMI $19-30 \mathrm{~kg} / \mathrm{m}^{2}$ ) were enrolled in the study. All subjects were in good general health based on medical history, physical examination, vital signs, electrocardiogram (ECG), laboratory measurements (serum biochemistry, haematology, hepatitis, HIV and urinalysis).

Safety assessments. Adverse events were monitored throughout the study period and a physical examination was performed at days 0 and 14. The ECG (12-lead) and vital signs (blood pressure, pulse rate, respiratory rate and temperature) were recorded the day before dosing, and before, during and after $\mathrm{t}_{\max }$ of $\mathrm{NN} 2211(9 \mathrm{~h})$ on all dosing days. Clinical laboratory samples (biochemistry, haematology, urinalysis) were taken the day before drug administration, on day 4 and 14 . The 24-h urine volumes were collected on day 1-2 (single dose) and day 11-12 (7 days of doses).

Pharmacokinetic assessments. Plasma samples (EDTA) for determination of NN2211 were collected at the following time points after the first dose and last dose administration on days 1 and 11: predose and 1, 2, 3, 4, 5, 6, 7, 8, 10, 12, 24, 36, 48, 60, 72 and $84 \mathrm{~h}$ after a dose was given. In addition trough samples were collected before doses were given on day $5,6,7,8,9,10$ and 11 . The concentration of NN2211 was determined by a validated two-site immuno-assay using a capturing antibody (GLPB1F1) and a detection antibody (biotin-labelled Mab26.1) both raised against native GLP-1 as described previously [31]. In each setup a calibration curve was included consisting of NN2211 in 0-plasma ranging from 18 to $4500 \mathrm{pmol} / \mathrm{l}$. The samples were obtained as EDTA plasma, if dilution of samples was needed it was done in normal human plasma.

In short, the assays were performed as follows: samples and calibrators were incubated at $37^{\circ} \mathrm{C}$ for $4 \mathrm{~h}$ in order to remove endogenous GLP-1 reactivity. Thereafter, $20 \mu 1$ sample or calibrator was transferred to the coated plate with $100 \mu \mathrm{l}$ buffer and incubation at $4{ }^{\circ} \mathrm{C}$ overnight. After a washing, the biotinlabelled Mab26.1 was applied, the plates were incubated, washed and a streptavidin-labelled peroxidase solution added followed by incubation. Finally, after washing, the enzyme substrate containing $\mathrm{H}_{2} \mathrm{O}_{2}$ and TMB was added and the colour reaction stopped after incubation by addition of $3 \mathrm{~N}$ phosphoric acid. The plates were read at $450 \mathrm{~nm}$ with $620 \mathrm{~nm}$ as reference and the concentrations calculated by extrapolation from the calibration curve.

The validation of the assay showed the following parameters. Assay repeatability was calculated at three concentrations (low, medium and high), and ranged from 2.4 to $6.5 \%$. The day-to-day assay variation at the same three concentrations ranged from $3.7-10.1 \%$. The linearity was tested with dilution up to 16 -fold. The mean linearity, expressed, as diluted sample result in per cent of undiluted sample result, was $106 \%$ (range: $93-118 \%)$. As the variation was acceptable, and the linearity 
was good at least up to 16 -fold dilution, samples could reliably be measured with concentrations at least up to $72000 \mathrm{pmol} / \mathrm{l}$ of NN2211. The lower limit of quantification (LLOQ) was determined to be $18 \mathrm{pmol} / \mathrm{l}$. The limit of detection (LOD) was 3 $\mathrm{pmol} / \mathrm{l}$. The recovery was examined in six different plasma samples. The mean recovery was $102 \%$ (range $93-113 \%$ ). Interference from a number of peptides was investigated. The NN2211 (7-37) isomer interfered positively but less than 4\%, NN2211 (9-37) isomer had negative interference less than $12 \%$, GLP-1 (15-37) had negative interference less than 3\%, MPGF (Major Pro Glucagon Fragment) had negative interference less than $4 \%$. Because all these interferences were low, and the concentrations of the peptides in the majority of the samples were low compared to the NN2211 concentrations, interference was considered irrelevant.

Derived pharmacokinetic parameters from the concentration data were calculated for each individual subject in each dosing group, by use of non-compartmental methods, using the commercially available software WinNonlin Version 2.1 (Pharsight, Cary, N.C., USA). The maximum serum concentration $\left(\mathrm{C}_{\max }\right)$ and the corresponding time $\left(\mathrm{t}_{\max }\right)$ were read directly from the concentration-time data. Area under the concentration-time curve was calculated by the trapezoidal rule from the time zero to $24 \mathrm{~h}\left(\mathrm{AUC}_{0-24}\right)$, and the last measurable serum concentration $\left(\mathrm{AUC}_{\mathrm{tn}-\infty}\right.$. The terminal elimination rate constant was estimated by log-linear regression on the terminal log-linear part of the concentration-time curve, and used for calculating the residual area from last measurable concentration to infinity $\left(\mathrm{AUC}_{\mathrm{tn}-\infty}\right)$, and the elimination half-life $\left(t_{1 / 2}\right)$. The AUC (to infinity) was calculated as the sum of $\mathrm{AUC}_{\mathrm{tn}}$ and $\mathrm{AUC}_{\mathrm{tn}-\infty}$. Oral clearance (CL/f) and the oral volume of distribution during the elimination phase $\left(\mathrm{V}_{\mathrm{z}} / \mathrm{f}\right)$ were calculated. The accumulation index was calculated as AUC day $7 /$ AUC day $1\left(R_{a c}\right)$.

Pharmacodynamic assessments. Plasma samples for insulin and glucose measurements were taken at the following time points after doses were given on day 1 and 11: predose and 1, 2, 3, 4, 5, $6,7,8,10,12$, and $24 \mathrm{~h}$. In accordance with the manufacturers instructions glucose was analysed by the enzymatic oxidation (am Trinder) method on a Hitachi 171 (Boehringer Mannheim, Copenhagen, Denmark), whereas insulin was analysed by ELISA (DAKO, code No. K6219). The two assays had an imprecision of 3 and $8 \%$, respectively. The area under the curve from time 0 to $24 \mathrm{~h}\left(\mathrm{AUC}_{0-24}\right)$ was calculated by the trapezoidal rule.

Statistical methods. Only data from subjects who had been given a dose and exposed to trial product on all study days 1 and 5-11 were included in the statistical analysis (due to low injection volumes and air in cartridges several subjects had exposure below LLOQ at the two lowest dose levels). Thus, three subjects had exposure below LLOQ at 1.25 , two at $5.0 \mu \mathrm{g} / \mathrm{kg}$, and in addition three subjects were withdrawn due to adverse events one at $1.25,7.5$, and $10 \mathrm{ug} / \mathrm{kg}$. Normal distribution of the data was assumed.

Safety. Non-transformed average volume of urine excreted over the 24-h sampling periods was analysed by ANOVA and $95 \%$-CI was calculated.

Pharmacokinetics. AUC, $\mathrm{C}_{\max }$, and $\mathrm{R}_{\mathrm{ac}}$ were logarithmically transformed before analysis and then subjected to ANOVA. Dose proportionality was assessed for AUC and $\mathrm{C}_{\max }$ and an estimate of the slope of the regression line and corresponding $95 \%$-CI were calculated. Dose proportionality was seen if the slope was not statistically significantly different from unity.
Pharmacodynamics. The 24-h profiles of glucose and insulin on days 1 and 11 were subjected to non-compartmental analysis. The $\mathrm{AUC}_{0-24}$ values on days 1 and 11 were included in the statistical analysis following log-transformation and analysed by ANOVA.

\section{Results}

Adverse events following NN2211 or placebo administration are presented in Table 1. Overall, there was a higher frequency of adverse events in the actively than in the placebo treated subjects. Three subjects were withdrawn due to adverse events, notably dizziness $(1.25 \mu \mathrm{g} / \mathrm{kg})$, fever and pharyngitis or both $(7.5 \mu \mathrm{g} / \mathrm{kg})$, and nausea and diarrhoea or both $(10 \mu \mathrm{g} / \mathrm{kg})$. Of these dizziness and nausea/diarrhoea were considered to be possibly related to NN2211 administration, whereas fever (seven days duration) was not considered to be related. There were no serious adverse events during the study. The most frequently reported adverse events were headache, dizziness and events related to the gastrointestinal system. In subjects treated with NN2211 compared to placebo, there was a higher frequency of dizziness and adverse events related to the gastrointestinal system. There were no clinically relevant changes in vital signs, ECG parameters, physical examination or safety laboratory parameters (haematology, biochemistry and urinalysis). Combined urine volume data (day 1 and 11) showed a statistically significant reduction following a dose of NN2211 compared to placebo treatment (95\%-CI [-885, -318]). The difference in packed cell volume (PCV) from day 0 to 14 was $0.0067 \pm 0.023$ in the placebo group compared with $-0.023 \pm 0.024$ in the actively treated subjects.

Figure 1 shows the concentration time profiles of NN2211 following s.c. administration, and the derived pharmacokinetic parameters are given in Table 2. NN2211 was slowly absorbed; with maximum plasma concentrations obtained approximately 10-14 $\mathrm{h}$ after a dose was given, and subsequent mean elimination half-life in the range of 11-13 h (Table 2). The mean accumulation ratio $\left(\mathrm{R}_{\mathrm{ac}}\right)$ was calculated to be in the range of 1.4 to 1.5 . The pharmacokinetic parameters calculated after one week of treatment was in accordance with those calculated on day 1 (Table 2). The statistical analysis showed a dose-proportional increase in $\mathrm{C}_{\max }$, and AUC following both single and repeated daily doses between $5-12.5 \mu \mathrm{g} / \mathrm{kg}$ administered s.c. to healthy subjects $(95 \%-\mathrm{CI}$ for day 1: $\mathrm{C}_{\max }[0.056,1.31]$, AUC $[0.099,1.078]$, and for day 11: $\mathrm{C}_{\max }[0.48,1.36]$, and AUC $\left.[0.28,1.27]\right)$. Plots of AUC and $\mathrm{C}_{\max }$ against the dose of NN2211 are shown in Figure 2. There was a statistically significant, accumulation $\left(\mathrm{R}_{\mathrm{ac}}=1.4-1.5\right)$ of NN2211 following repeated daily administration, except for the $5.0 \mu \mathrm{g} / \mathrm{kg}$ dose level $(95 \%$-CI $[0.83,1.7])$. 
198

H. Agers $\varnothing$ et al.: Multiple dosing with NN2211 in healthy men

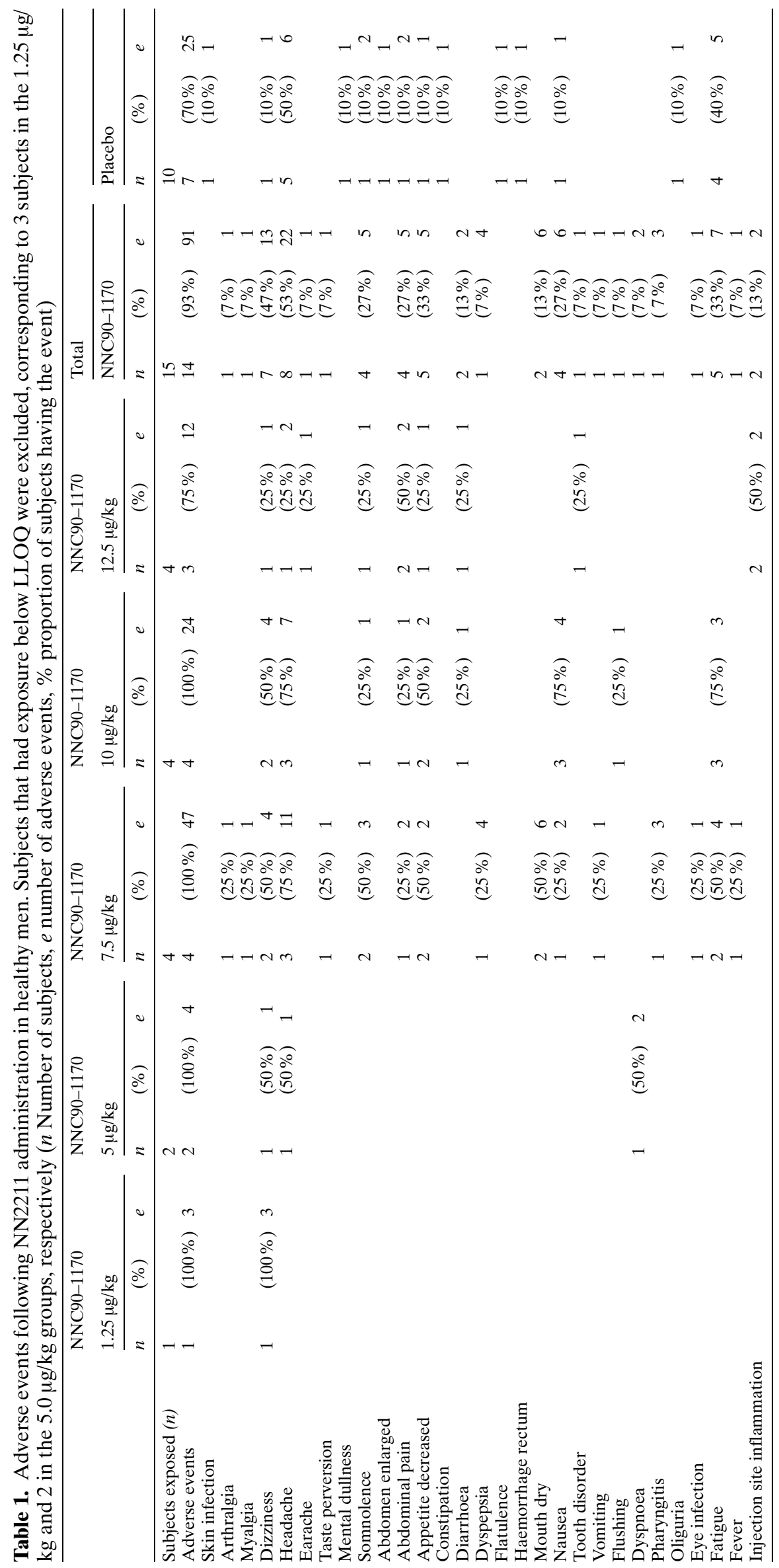




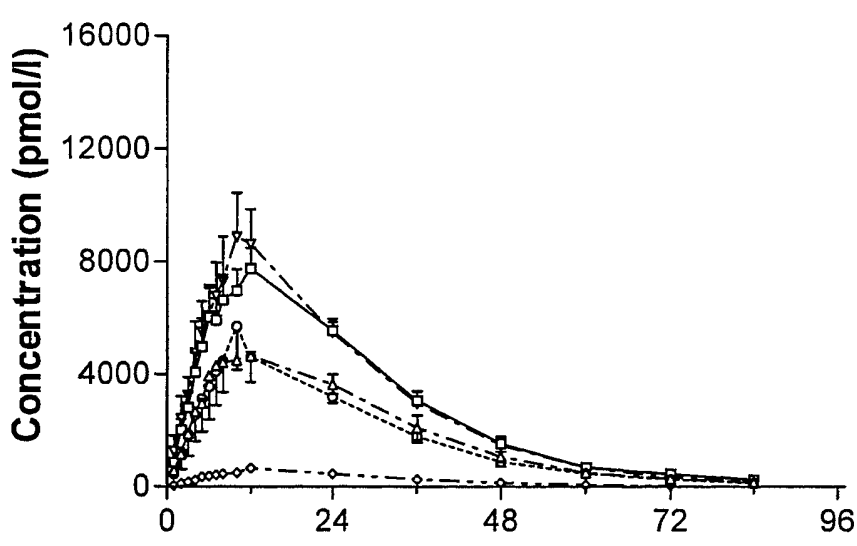

A

Time (h)

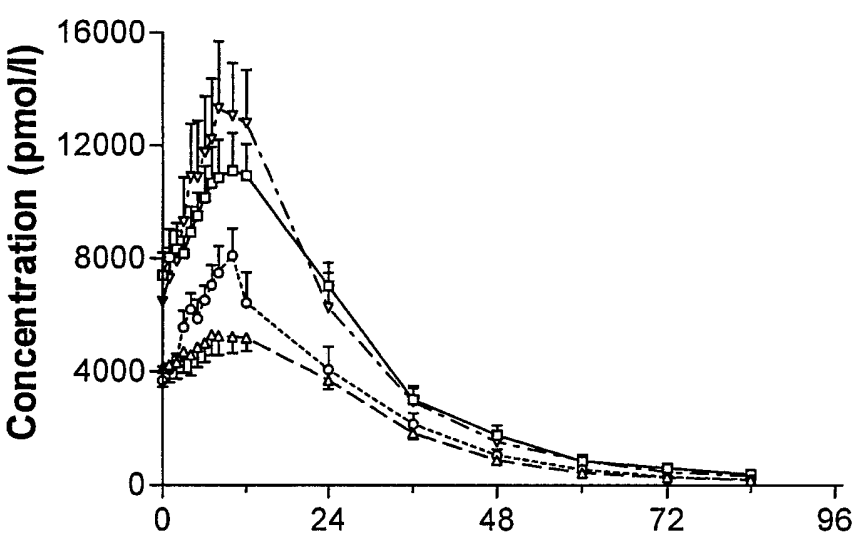

Time (h)

Fig. 1. Mean NN2211 plasma concentration (pmol/l) $( \pm$ SEM) versus time (h) profiles after s.c. administration of NN2211 to healthy men following a single dose $---\diamond---1.25 \mu \mathrm{g} / \mathrm{kg}$, $--\triangle--5 \mu \mathrm{g} / \mathrm{kg}, \quad--\bigcirc--7.5 \mu \mathrm{g} / \mathrm{kg}, \quad-\square-10 \mu \mathrm{g} / \mathrm{kg}$, $---\nabla---12.5 \mu \mathrm{g} / \mathrm{kg}$ (A), and 7 days of daily s.c. dosing $---\triangle---5 \mu \mathrm{g} / \mathrm{kg},---\bigcirc---7.5 \mu \mathrm{g} / \mathrm{kg},---\square---10 \mu \mathrm{g} / \mathrm{kg}$, $---\nabla---12.5 \mu \mathrm{g} / \mathrm{kg}(\mathbf{B})$

The mean insulin and glucose time profiles are shown in Figure 3 and 4, respectively. Overall, for the 24 -h profiles, there was no statistically significant

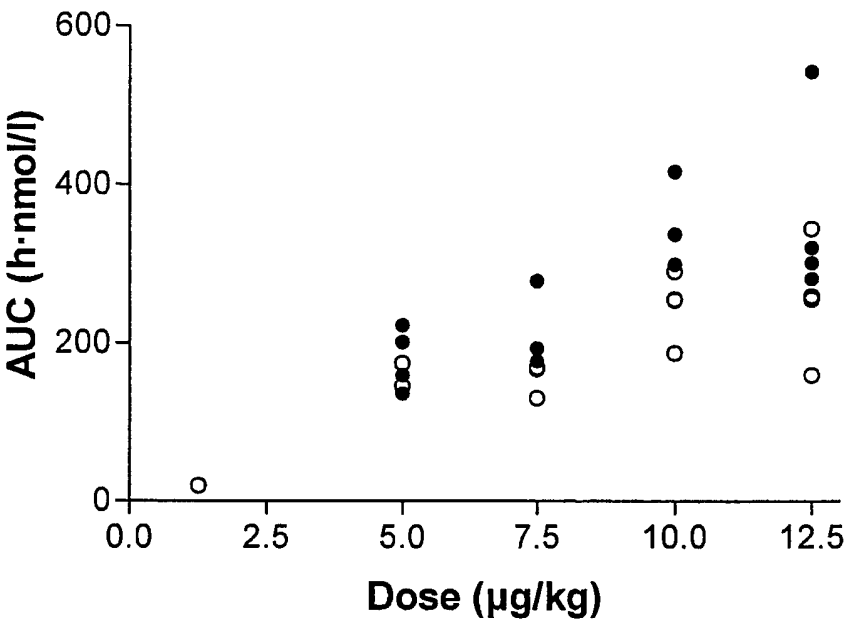

Fig. 2. Mean NN2211 plasma concentration AUC (h · nmol/l) versus dose $(\mu \mathrm{g} / \mathrm{kg})$ after s.c. administration of NN2211 to healthy volunteers at 5 different dose levels; following a single dose on day $1(\bigcirc)$, and following 7 days of consecutive dosing on day 11

difference between active and placebo treatment (glucose $95 \%$-CI $[0.89,1.04]$, insulin $95 \%$-CI [0.84, 1.22]). However, corresponding to $t_{\max }$ of $\mathrm{NN} 2211$ (and meals) a reduction of insulin concentrations was observed in the actively treated subjects. Furthermore, higher glucose concentrations in the placebo treated subjects were found, most pronounced in connection to meals giving lower post-prandial glucose concentrations (corresponding to 2,5 , and $12 \mathrm{~h}$ ) in the actively treated subjects as compared to the placebo group (Fig. 5).

\section{Discussion}

The findings in this study of an increase in gastrointestinal side effects following NN2211 is in accordance with previous reports on GLP-1 [3,23]. The effect is probably a consequence of GLP-1's effect on reducing gastric emptying $[11,12,32,33]$. In addition

Table 2. Mean pharmacokinetic parameters of NN2211 on day 1 and day 11

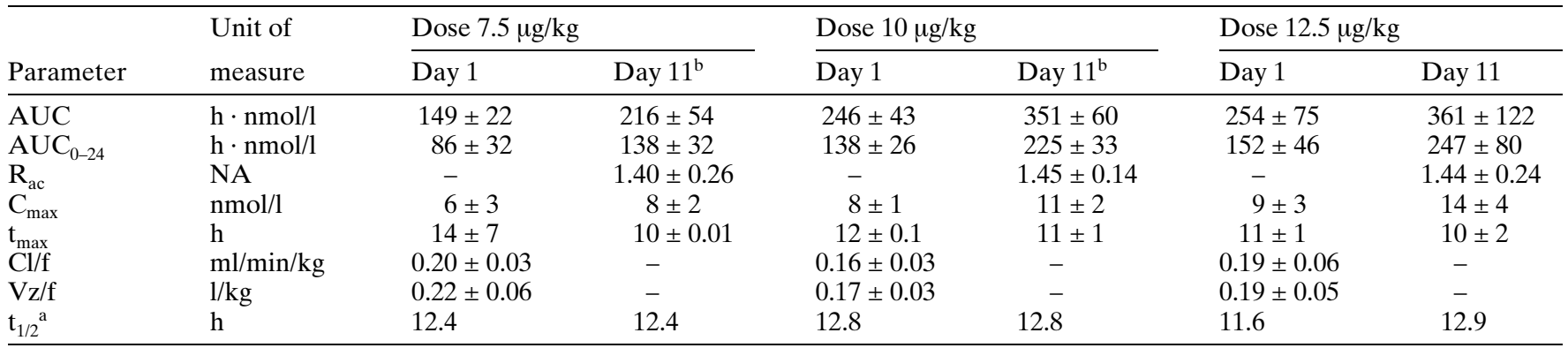

$n$ equals 4 unless otherwise indicated

${ }^{\text {a}}$ Harmonic mean

${ }^{\mathrm{b}}$ Mean of 3 subjects 


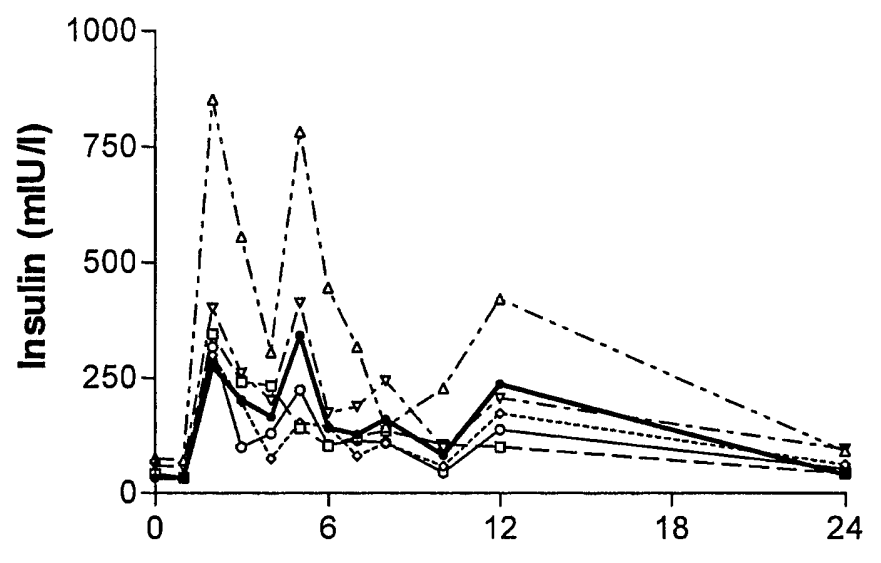

A

Time (h)

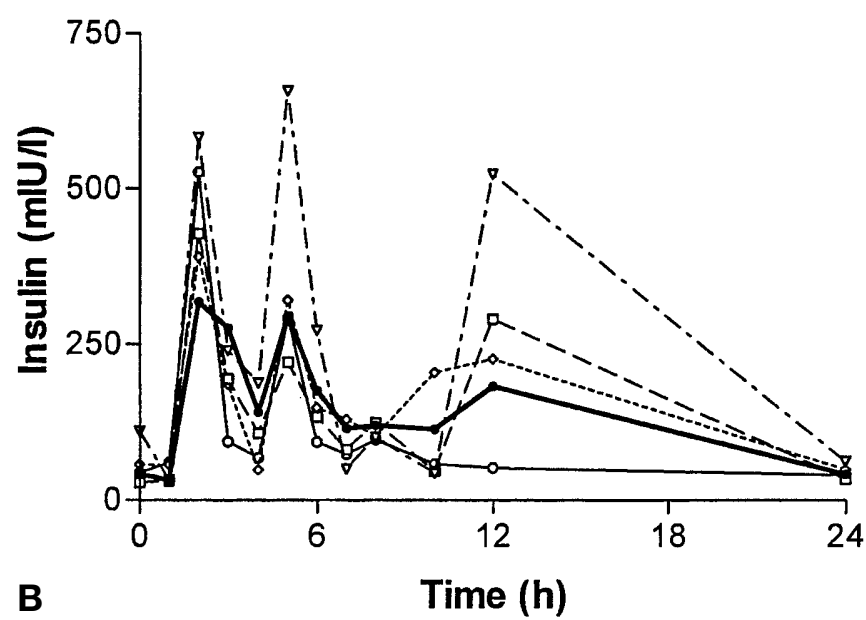

Fig. 3. Mean insulin versus time concentration (mlU/l) versus time (h) profiles following a single dose - - placebo, $---\triangle---1.25 \mu \mathrm{g} / \mathrm{kg},---\nabla---5 \mu \mathrm{g} / \mathrm{kg},--\square--7.5 \mu \mathrm{g} / \mathrm{kg}$, - - $\diamond-\cdots-10 \mu \mathrm{g} / \mathrm{kg},-\bigcirc-12.5 \mu \mathrm{g} / \mathrm{kg}(\mathbf{A})$, and 7 days of daily s.c. dosing - - placebo, -- $-\nabla--5 \mu \mathrm{g} / \mathrm{kg}$, $--\square--7.5 \mu \mathrm{g} / \mathrm{kg},-\cdots--_{-} 10 \mu \mathrm{g} / \mathrm{kg},-\bigcirc-12.5 \mu \mathrm{g} / \mathrm{kg}$ (B). Breakfast, lunch and dinner were served at 1,4 and $11 \mathrm{~h}$ after doses were given

there was a higher frequency of dizziness reported after NN2211 compared with placebo administration, which is in accordance with a previous report following 7 days GLP-1 infusion [23]. Finally, a significant reduction in urine volume $(0-24 \mathrm{~h})$ was observed in this study following NN2211 treatment. As GLP-1 administration has been shown to reduce water intake [1], the reduced urine volume could be secondary to this, even though water intake was not assessed in this study. The reduced urine volume was not followed by a clinically relevant change in packed cell volume from day 0 to 14 , suggesting that it was not followed by dehydration.

Native GLP-1 has a half-life following i.v. or s.c. administration in human beings of approximately $5 \mathrm{~min}$ [1] and $1 \mathrm{~h}$ [2], respectively. The pharmacokinetic profile of NN2211 demonstrated in this study with a mean elimination half life of $12.6 \pm 1.1 \mathrm{~h}$ is
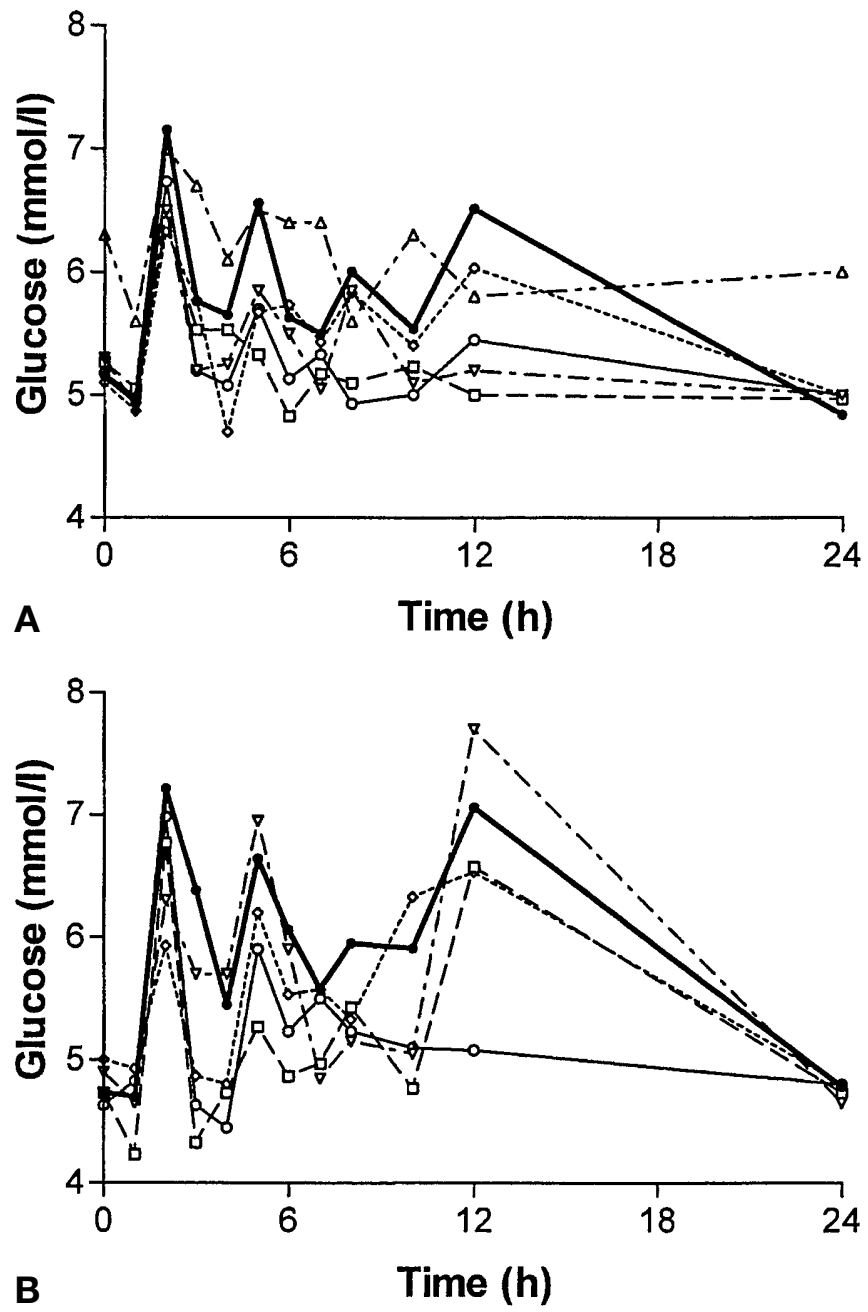

Fig. 4. Mean glucose versus time concentration (mmol/l) versus time (h) profiles following a single dose - - placebo, $---\triangle---1.25 \mu \mathrm{g} / \mathrm{kg},---\nabla---5 \mu \mathrm{g} / \mathrm{kg},--\square--7.5 \mu \mathrm{g} / \mathrm{kg}$, - - $\diamond-\cdots 10 \mu \mathrm{g} / \mathrm{kg},-\bigcirc-12.5 \mu \mathrm{g} / \mathrm{kg}(\mathbf{A})$ and seven days of daily s.c. dosing - - placebo, --- $----5 \mu \mathrm{g} / \mathrm{kg}$, $--\square--7.5 \mu \mathrm{g} / \mathrm{kg},---\diamond---10 \mu \mathrm{g} / \mathrm{kg},-\bigcirc-12.5 \mu \mathrm{g} / \mathrm{kg}$ (B). Breakfast, lunch and dinner were served at 1,4 and $11 \mathrm{~h}$ after the dose

consistent with a previous single dose study in human beings [27]. The steady-state pharmacokinetic parameters were similar to those following a single dose. There was a slight but statistically significant accumulation of NN2211 following a daily s.c. administration to healthy subjects, as indicated by the mean accumulation ratio (Table 1). The protraction mechanism of NN2211 compared with native GLP-1 probably relies on a combination of albumin binding, as has been shown for other fatty acid derivatives [24, 25], lower susceptibility to metabolism by DPP-IV [34], and a slower absorption profile. Taken together these data indicate that a daily dose of NN2211 can be beneficial to human beings.

In this study, there was no conclusive indication that NN2211 stimulated insulin concentrations above placebo. This could be because the effects on gastric 

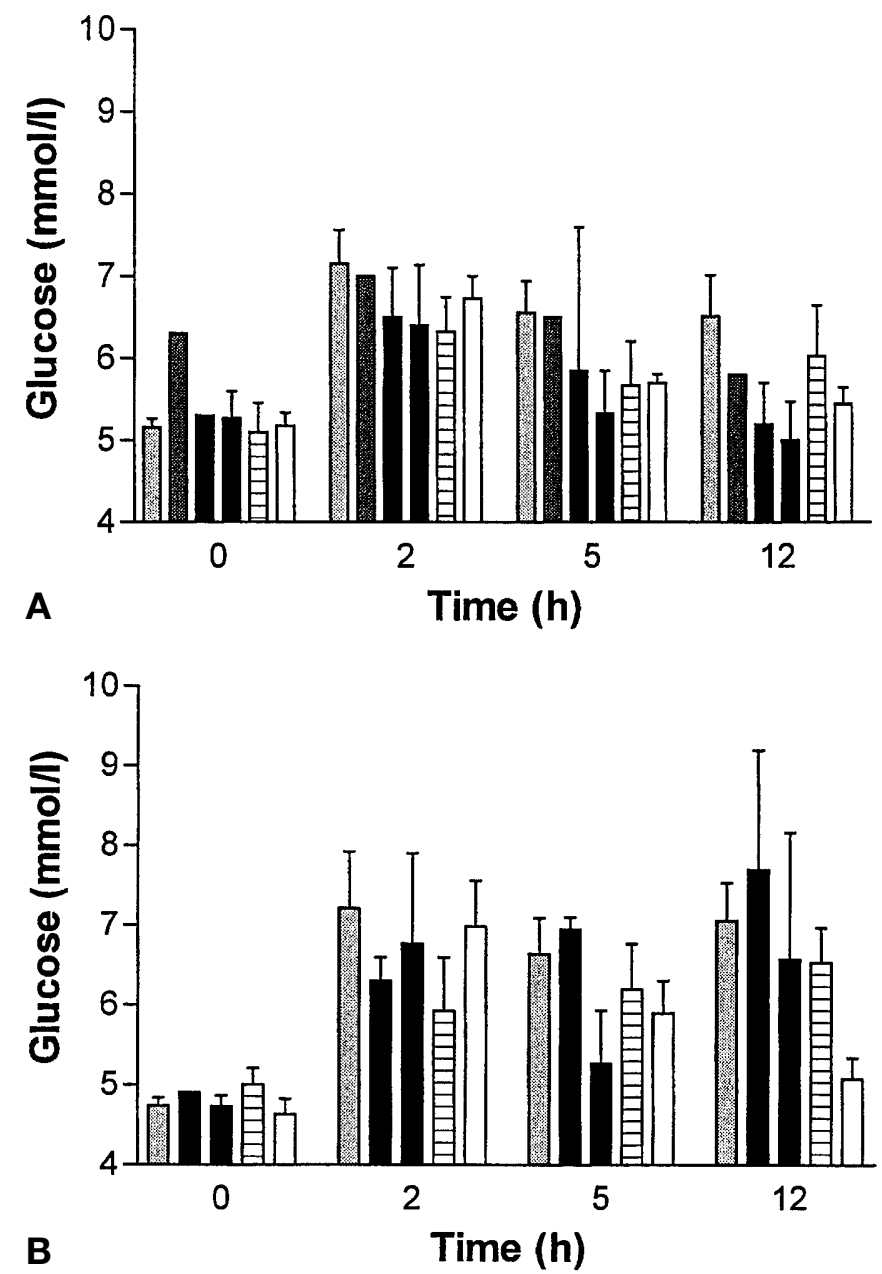

Fig. 5. Mean ( \pm SEM) rise in plasma glucose concentrations (mmol/l) at time of dosing (tasting) after breakfast, lunch and dinner a single dose (lightly shaded bars) placebo, (moderately shaded bars) $1.25 \mu \mathrm{g} / \mathrm{kg}$, (heavily shaded bars) $5 \mu \mathrm{g} / \mathrm{kg}$, (solid bars) $7.5 \mu \mathrm{g} / \mathrm{kg}$, (bars with line through) $10 \mu \mathrm{g} / \mathrm{kg}$, (empty bars) $12.5 \mu \mathrm{g} / \mathrm{kg}$ (A) and seven days of daily s. c. dosing (lightly shaded bars) placebo, (darkly shaded bars) $5 \mu \mathrm{g} / \mathrm{kg}$, (solid bars) $7.5 \mu \mathrm{g} / \mathrm{kg}$, (bars with line through) $10 \mu \mathrm{g} / \mathrm{kg}$, (empty bars) $12.5 \mu \mathrm{g} / \mathrm{kg}$ (B). Breakfast, lunch and dinner were served at 1,4 and $11 \mathrm{~h}$ after a dose

emptying by GLP-1 could outweigh the effects on the insulin secretion in healthy volunteers, as described previously [34]. The latter study reported insulin concentrations following a meal to be significantly lower in the active compared to the placebo treated group [34]. Thus, although insulin secretion was stimulated by GLP-1, the glucose-mediated stimulation was less profound because of the inhibition of gastric emptying, and in sum this gave lower insulin concentrations (i.e. the gastric effect outweighed the insulin secretion effect). This is consistent with the lower insulin levels observed following meals and maximal plasma concentrations of NN2211 in this study. In line with this, it has been speculated that the primary effect of native GLP-1 in healthy subjects could be to inhibit gastric empty- ing rate and mediate satiety, rather than acting as an incretin hormone [35] (in this study decreased appetite was reported at a higher frequency in actively compared placebo treated subjects). However, even though the effects on the insulin secretion could have been scattered by the concomitant effect on gastric emptying time, the glucose concentrations indicate a combined effect. In this study, there was a general trend towards lower mean glucose concentrations following active treatment as compared to placebo, i.e. the mean glucose concentrations at approximately 2,5 and $12 \mathrm{~h}$ following breakfast, lunch and dinner at 1,4 and $11 \mathrm{~h}$ after a dose was given. Similar findings were reported previously in healthy human beings [33]. Furthermore, the relatively modest changes in glucose concentrations observed here and previously, are consistent with a GLP-1 glucose dependent mechanism of action [8]. In this study, glucagon was not measured, however, following a single dose with NN2211 in healthy men no significant effect on glucagon was observed [27]. The data presented suggest that a therapeutic dose range for NN2211 could be from $1-10 \mu \mathrm{g} / \mathrm{kg}$ in patients with Type II diabetes. However this will depend on a combination of efficacy and side effect profile of NN2211 in this cohort.

In summary, subjects treated with NN2211, had a higher incidence of adverse events than those given a placebo, most notably dizziness and adverse events related to the gastrointestinal system. While there were no serious adverse events, three subjects were withdrawn due to adverse events. Significantly lower 24-h diuresis was observed in the actively treated subjects, without a clinically relevant change in PCV. No statistically significant changes in insulin or glucose were found but a reduction in glucose concentrations after meals was observed in NN2211 treated subjects, supporting the notion that the effects of GLP-1 on glucose is not only mediated by insulin but, more importantly, through inhibition of gastric emptying. Furthermore, the pharmacokinetic data showed that NN2211 has a markedly protracted profile in human beings. In contrast to other known GLP-1 like compounds, notably LY307161 [36, 37] and exendin-4 (AC2993) [38], the findings presented here suggest that NN2211 has sufficient protraction to cover a daily dose administration in human beings. This is important not only for improving compliance and convenience for the patients but also in realising full therapeutic potential, as it was recently shown that in order to achieve acceptable control in patients with Type II diabetes who were poorly controlled on sulphonylurea treatment 24-h GLP-1 infusion had to be maintained [23].

Acknowledgements. The thoughtful comments on the manuscript by Dr. L. Bjerre Knudsen, Novo Nordisk, were highly appreciated. 


\section{References}

1. Kiefer TJ, Habener JF (1999) The glucagon-like peptides. Endocr Rev 20: 876-913

2. Gutniak MK, Linde B, Holst JJ, Efendic S (1994) Subcutaneous injection of the incretin hormone glucagon-like peptide 1 abolishes postprandial glycemia in NIDDM. Diabetes Care 17: 1039-1044

3. Nauck MA, Wollschlager D, Werner J et al. (1996) Effects of subcutaneous glucagon-like peptide 1 (GLP-1 [7-36 amide]) in patients with NIDDM. Diabetologia 39: 1546-1553

4. Nauck MA, Sauerwald A, Ritzel R, Holst JJ, Schmiegel W (1998) Influence of glucagon-like peptide 1 on fasting glycemia in type 2 diabetic patients treated with insulin after sulfonylurea secondary failure. Diabetes Care 21: 1925-1931

5. Qualmann C, Nauck MA, Holst JJ, Ørskov C, Creutzfeldt W (1995) Insulinotropic actions of intravenous glucagon-like peptide-1 (GLP-1) [7-36 amide] in the fasting state in healthy subjects. Acta Diabetol 32: 13-16

6. Toft-Nielsen MB, Madsbad S, Holst JJ (1999) Continuous subcutaneous infusion of glucagon-like peptide 1 lowers plasma glucose and reduces appetite in type 2 diabetic patients. Diabetes Care 22: 1137-1143

7. Nauck MA, Kleine N, Ørskov C, Holst JJ, Willms B, Creutzfeldt W (1993) Normalization of fasting hyperglycaemia by exogenous glucagon-like peptide 1 (7-36 amide) in Type II (non-insulin-dependent) diabetic patients. Diabetologia 36: 741-744

8. Holst JJ, Ørskov C, Nielsen OV, Schwartz TW (1987) Truncated glucagon-like peptide I, an insulin-releasing hormone from the distal gut. FEBS Lett 211: 169-174

9. Kreymann B, Williams G, Ghatei MA, Bloom SR (1987) Glucagon-like peptide-1 7-36: a physiological incretin in man. Lancet ii: $1300-1304$

10. Wettergren A, Schjoldager B, Mortensen PE, Myhre J, Christiansen J, Holst JJ (1993) Truncated GLP-1 (proglucagon 78-107-amide) inhibits gastric and pancreatic functions in man. Dig Dis Sci 38: 665-673

11. Naslund E, Gutniak M, Skogar S, Rossner S, Hellstrom PM (1998) Glucagon-like peptide 1 increases the period of postprandial satiety and slows gastric emptying in obese men. Am J Clin Nutr 68: 525-530

12. Naslund E, Barkeling B, King N et al. (1999) Energy intake and appetite are suppressed by glucagon-like peptide-1 (GLP-1) in obese men. Int J Obes Relat Metab Disord 23: 304-311

13. Edvell A, Lindstrom P (1999) Initiation of increased pancreatic islet growth in young normoglycemic mice (Umea $+/$ ?). Endocrinology 140: 778-783

14. Nauck MA, Heimesaat MM, Ørskov C, Holst JJ, Ebert R, Creutzfeldt W (1993) Preserved incretin activity of glucagonlike peptide $1-7-36$ amide- but not of synthetic human gastric inhibitory polypeptide in patients with type-2 diabetes mellitus. J Clin Invest 91: 301-307

15. Rachman J, Barrow BA, Levy JC, Turner RC (1997) Near-normalisation of diurnal glucose concentrations by continuous administration of glucagon-like peptide-1 (GLP-1) in subjects with NIDDM. Diabetologia 40: 205-211

16. Willms B, Werner J, Holst JJ, Ørskov C, Creutzfeldt W, Nauck MA (1996) Gastric emptying, glucose responses, and insulin secretion after a liquid test meal: effects of exogenous glucagonlike peptide-1 (GLP-1)-(7-36) amide in type 2 (noninsulin-dependent) diabetic patients. J Clin Endocrinol Metab 81: 327-332

17. Nathan DM, Schreiber E, Fogel H, Mojsov S, Habener JF (1992) Insulinotropic action of glucagonlike peptide-I-(7-37) in diabetic and nondiabetic subjects. Diabetes Care 15: 270-276

18. Creutzfeldt WO, Kleine N, Willms B, Ørskov C, Holst JJ, Nauck MA (1996) Glucagonostatic actions and reduction of fasting hyperglycemia by exogenous glucagon-like peptide I(7-36) amide in type I diabetic patients. Diabetes Care 19: 580-586

19. Gutniak M, Orskov C, Holst JJ, Ahren B, Efendic S (1992) Antidiabetogenic effect of glucagon-like peptide-1 (7-36)amide in normal subjects and patients with diabetes mellitus. N Engl J Med 326: 1316-1322

20. Mentlein R, Gallwitz B, Schmidt WE (1993) Dipeptidyl-peptidase IV hydrolyses gastric inhibitory polypeptide, glucagon-like peptide-1(7-36)amide, peptide histidine methionine and is responsible for their degradation in human serum. Eur J Biochem 214: 829-835

21. Knudsen LB, Nielsen PF, Huusfeldt PO et al. (2000) Potent derivatives of gglucagon-like peptide-1 with pharmacokinetic properties suitable for once daily aministration. J Med Chem 43: 1664-1669

22. Pridal L, Deacon CF, Kirk O, Christensen JV, Carr RD, Holst JJ (1996) Glucagon-like peptide-1(7-37) has a larger volume of distribution than glucagon-like peptide-1(7-36)amide in dogs and is degraded more quickly in vitro by dog plasma. Eur J Drug Metab Pharmacokinet 21: 51-59

23. Larsen J, Hylleberg B, Ng K, Damsbo P (2001) Glucagon-Like Peptide-1 infusion must be maintained for 24 hours a day in order to obtain acceptable glycemia in type 2 diabetic patients who are poorly controlled on treatment with sulphonylurea (SU failures). Diabetes Care 24: 1416-1421

24. Kurtzhals P, Havelund S, Jonassen I et al. (1995) Albumin binding of insulins acylated with fatty acids: characterization of the ligand-protein interaction and correlation between binding affinity and timing of the insulin effect in vivo. Biochem $\mathbf{J} 312$ : 725-731

25. Markussen J, Havelund S, Kurtzhals P et al. (1996) Soluble, fatty acid acylated insulins bind to albumin and show protracted action in pigs. Diabetologia 39: 281-288

26. Chou JZ, Place GD, Waters DG, Kirkwood JA, Bowsher RR (1997) A radioimmunoassay for LY315902, an analog of glucagon-like insulinotropic peptide, and its application in the study of canine pharmacokinetics. J Pharm Sci 86: 768-773

27. Jakobsen G, Agers $\varnothing$ H, Elbroend B, Jensen LB (2001) Pharmacokinetic profile of the long-acting GLP-1 derivative NN2211 in healthy male subjects. Diabetes 50 [Suppl 1]: 472

28. Ribel U, Hvidt M, Larsen MO, Rolin B, Wilken M, Knudsen LB (2000) Glucose lowering of the protracted GLP-1 derivative, NN2211, in the $\beta$-cell reduced minipig. Diabetologia 43 [Suppl 1]: 560

29. Sturis J, Jappe MB, Knudsen LB (2000) The long acting GLP-1 derivative NN2211 markedly slows the development of diabetes in the male zucker diabetic fatty rat. Diabetes 50 [Suppl 1]: 943

30. Larsen MO, Rolin B, Wilken M, Carr RD, Knudsen LB (2000) NN2211, a long acting derivative of GLP-1, lowers blood glucose in ob/ob and db/db mice. Diabetes 50 [Suppl 1]: 4

31. Wilken M, Larsen FS, Juul AG, Jensen LB, Ribel U (2000) An Immunoassay for the GLP-1 derivative NN2211. Diabetologia 43 [Suppl 1]: 143

32. Gutzwiller JP, Drewe J, Goke B et al. (1999) Glucagon-like peptide-1 promotes satiety and reduces food intake in patients with diabetes mellitus type 2. Am J Physiol 276: R1541-R1544

33. Gutzwiller JP, Goke B, Drewe J et al. (1999) Glucagon-like peptide-1: a potent regulator of food intake in humans. Gut 44: $81-86$

34. Nauck MA, Niedereichholz U, Ettler R et al. (1997) Glucagonlike peptide 1 inhibition of gastric emptying outweighs its insulinotropic effects in healthy humans. Am J Physiol 273: E981-E988

35. Nauck MA (1999) Is glucagon-like peptide 1 an incretin hormone? Diabetologia 42: 373-379

36. Myers S, Workman R, Clephane M (2000) LY307161: a proteaseprotected analogue of GLP-1, with enhanced activity and time action in vivo. Diabetologia 43 [Suppl 1]: 562

37. Pascoe S, Payne C, Trautmann M (2000) The GLP-1 analogue, LY307161, potently lowers post prandial blood glucose in subjects with Type II diabetes. Diabetologia 43 [Suppl 1]: 122

38. Buse J, Fineman M, Gottlieb A et al. (2000) Effects of five-day dosing of synthetic exendin-4 (AC2993) in people with type 2 diabetes. Diabetes 49 [Suppl 1]: 402 